\title{
Early blood glucose profile and neurodevelopmental outcome at two years in neonatal hypoxic-ischaemic encephalopathy
}

\author{
Montasser Nadeem', Deirdre M Murray², Geraldine B Boylan², Eugene M Dempsey¹, Cornelius A Ryan ${ }^{1 *}$
}

\begin{abstract}
Background: To examine the blood glucose profile and the relationship between blood glucose levels and neurodevelopmental outcome in term infants with hypoxic-ischaemic encephalopathy.

Methods: Blood glucose values within 72 hours of birth were collected from 52 term infants with hypoxicischaemic encephalopathy. Hypoglycaemia $[<46.8 \mathrm{mg} / \mathrm{dL}(2.6 \mathrm{mmol} / \mathrm{L})]$ and hyperglycaemia $[>150 \mathrm{mg} / \mathrm{dL}(8.3$ $\mathrm{mmol} / \mathrm{L})]$ were correlated to neurodevelopmental outcome at 24 months of age.

Results: Four fifths of the 468 blood samples were in the normoglycaemic range (392/468:83.8\%). Of the remaining 76 samples, $51.3 \%$ were in the hypoglycaemic range and (48.7\%) were hyperglycaemic. A quarter of the hypoglycaemic samples (28.2\%:11/39) and a third of the hyperglycaemic samples (32.4\%:12/37) were recorded within the first 30 minutes of life. Mean (SD) blood glucose values did not differ between infants with normal and abnormal outcomes $[4.89(2.28) \mathrm{mmol} / \mathrm{L}$ and $5.02(2.35) \mathrm{mmol} / \mathrm{L}, \mathrm{p}$ value $=0.15]$ respectively. In term infants with hypoxic-ischaemic encephalopathy, early hypoglycaemia (between 0-6 hours of life) was associated with adverse outcome at 24 months of age [OR $=5.8, \mathrm{Cl}=1.04-32)]$. On multivariate analysis to adjust for grade of HIE this association was not statistically significant. Late hypoglycaemia (6-72 hours of life) was not associated with abnormal outcome $[\mathrm{OR}=0.22, \mathrm{Cl}(0.04-1.14)]$. The occurrence of hyperglycaemia was not associated with adverse outcome.
\end{abstract}

Conclusion: During the first 72 hours of life, blood glucose profile in infants with hypoxic-ischaemic encephalopathy varies widely despite a management protocol. Early hypoglycaemia (0-6 hours of life) was associated with severe $\mathrm{HIE}$, and thereby; adverse outcome.

\section{Background}

Hypoxic-ischaemic encephalopathy (HIE) remains an important cause of neonatal death and long-term neurodisability [1]. Goals of management have been to maintain normoxaemia, normocapnia, normoglycaemia and normal blood pressure to avoid or ameliorate secondary cerebral injuries [2].

Neonatal hypoglycaemia, independent of HIE, has been associated with adverse outcome in both term and preterm infants [3-5]. However, no conclusive evidence on the severity and duration of hypoglycaemia causing brain damage has been reported [6,7]. Basu et al showed

\footnotetext{
* Correspondence: tonyryan007@gmail.com

${ }^{1}$ Neonatal Intensive Care Unit, Cork University Maternity Hospital, Cork, Ireland

Full list of author information is available at the end of the article
}

that the degree of hypoglycaemia was correlated to the severity of HIE in term asphyxiated newborns [8]. In term infants with severe fetal acidemia, an association between early adverse outcome and hypoglycaemia on the first blood sample was reported by Salhab et al [9]. These studies did not address long-term neurodevelopmental outcome. The mechanism of hypoglycaemic brain injury has been examined in animal models. Hypoglycaemia decreases the cerebrovascular response to hypoxia and increases cerebral superoxide production and aspartate levels into the brain extracellular space resulting in neuronal necrosis [10-12].

Hyperglycaemia is associated with adverse outcome in premature infants, in critically ill children and in adult patients with stroke [13-18]. In extremely low birth weight infants and in patients in paediatric intensive

\section{() Biomed Central}


care unit, controlling elevated blood glucose levels by controlled insulin infusion was associated with good short-term outcome $[19,20]$. However, no data on longterm neurodevelopmental outcome relating to hyperglycaemia in neonatal HIE has been reported $[19,20]$. The mechanism of hyperglycaemic brain damage is thought to be related to neuronal cell apoptosis following reperfusion with high level of substrate (glucose) in an ATP- deleted cell. In an animal model, hyperglycaemia following hypoxic-ischaemic insult decreases fetal brain ATP and oxygen consumption and increases thickness of vascular endothelium with foci of infarction [21-23].

In the absence of long-term neurodevelopmental outcomes on the effects of early hypoglycaemia and hyperglycaemia in HIE, the aim of this study was to describe the early blood glucose profile and to determine whether hypoglycaemia and hyperglycaemia in the 72 hours of birth were associated with adverse neurodevelopmental outcome at 24 months of age in infants with HIE.

\section{Methods}

This study was a retrospective analysis of a prospective cohort of babies with HIE, none of whom received therapeutic hypothermia. It was conducted in a large maternity hospital with an annual delivery rate of approximately 5000 babies. Ethical approval was obtained from Cork University Hospital Research Ethics Committee. Informed consent was obtained from all parents of the infants who were enrolled in the study. We examined the medical notes of a cohort of 55 term infants with HIE, recruited prospectively at birth between May 2003 and December 2005. Term infants were recruited to the cohort if they fulfilled 2 or more of the following criteria:

- Initial capillary or arterial $\mathrm{pH}<7.1$

- Apgar score $<5$ at 5 minutes

- Initial capillary or arterial lactate $>7 \mathrm{mmol} / \mathrm{l}$

- Abnormal neurology or clinical seizures.

Demographics and data related to neonatal course, ventilation variables and the arterial, capillary and venous blood glucose values of the first 3 days of life were retrieved from the medical notes. All infants with HIE had blood glucose levels checked within the first 30 minutes after delivery. Blood glucose values were collected from either arterial, venous, or capillary samples. An onsite analyser (Radiometer) was used to measure blood glucose levels. Hypoglycaemia and hyperglycaemia were defined as blood glucose levels $<46.8 \mathrm{mg} / \mathrm{dL}(2.6 \mathrm{mmol} /$ L) and $>150 \mathrm{mg} / \mathrm{dL}(8.3 \mathrm{mmol})$ respectively $[5,13]$.

Hypoglycaemia was treated with an initial parenteral bolus of $2 \mathrm{~mL} / \mathrm{kg}$ of a $10 \%$ dextrose solution over one minute. Blood glucose levels were rechecked 30 minutes to 1 hour later according to the severity of hypoglycaemia. Dextrose infusion rate or concentration was adjusted to maintain blood glucose level $>50 \mathrm{mg} / \mathrm{dL}$ $(2.8 \mathrm{mmol} / \mathrm{L})$. In infants with hyperglycaemia, the rate or concentration of glucose infusion was adjusted to maintain blood glucose within normal levels.

Demographic details and clinical data were recorded in each case. Clinical grade of encephalopathy was assigned using a Sarnat score at 24 hours of age. Neurodevelopmental outcome was assessed at 24 months using the Revised Griffith's scales of Mental Development [24]. Adverse outcome was defined as death, a Griffith's Quotient (GQ) less than 87, or significant motor disability. Statistical analysis was performed using SPSS version 14.0 for Windows. Summary measures were calculated and are reported as mean and standard deviation (SD) or median and (range). Spearman correlation was used to explore the differences in categorical variables. Univariate and multivariate logistic regression models were used to estimate odds ratios and 95\% confidence intervals. A $p$ value $<0.05$ was considered statistically significant.

\section{Results}

\section{Demographics (table 1)}

Fifty-two of the 55 infants completed follow up to 24 months. Mean (SD) gestational age was 39 weeks+1 day (1.5 weeks), mean (SD) birth weight was 3.45 (0.58) Kgs. Four infants were delivered at home, and therefore accurate details of Apgar scores and resuscitation details were not available. More than 1 bolus of dextrose infusion was required in four infants. All infants who required increased glucose infusions experienced stable blood glucose within 2 hours of birth.

\section{2-hour glucose profile}

In total, 468 blood glucose samples were analyzed. Four out of 5 samples were in the normoglycaemic range (392/468: 83.8\%). Of the remaining 76 samples, half (51.3\%) were in the hypoglycaemic range and less than half were hyperglycaemic (48.7\%).

The median timing of initial blood glucose sampling was 25 and 80 minutes after birth (range 9-30 and 70-100 minutes) in inborn and outborn infants respectively. More than one third of all blood samples [177/ $468(37.8 \%)]$ were documented within the first 6 hours of birth. A quarter of the hypoglycaemic (28.2\%: 11/39) and a third of the hyperglycaemic samples $(32.4 \%: 12 / 37)$ were recorded on the first blood samples. Fifty percent (20/39) of the hypoglycaemic and $90 \%(33 / 37)$ of the hyperglycaemic samples were recorded within the first 6 hours of life (figure 1).

Of the 52 infants in the cohort, mild, moderate and severe HIE was seen in 25, 18 and 9 infants, respectively. 
Table 1 Demographic data

\begin{tabular}{|c|c|}
\hline Total number of infants, $n$ & 52 \\
\hline Male, n (\%) & $34 / 52(65.4 \%)$ \\
\hline $\begin{array}{l}\text { Infants required ETT at } \\
\text { delivery, } \mathrm{n}(\%)\end{array}$ & $32 / 52(61.5 \%)$ \\
\hline $\begin{array}{l}\text { Infants required CPR at } \\
\text { delivery, } \mathrm{n}(\%)\end{array}$ & 13/52 (25\%) \\
\hline $\begin{array}{l}\text { Birth Weight, median } \\
\text { (range) }\end{array}$ & $3.54(1.83-5.04)$ \\
\hline $\begin{array}{l}\text { Gestational age (weeks } \\
\text { +days), median (range) }\end{array}$ & $40+1(35+6-42+1)$ \\
\hline $\begin{array}{l}\text { Apgar at } 1 \text { minute, median } \\
\text { (range) }\end{array}$ & $4(0-9)$ \\
\hline $\begin{array}{l}\text { Apgar at } 5 \text { minutes, } \\
\text { median (range) }\end{array}$ & $6(2-10)$ \\
\hline $\begin{array}{l}\text { Blood glucose, median } \\
\text { (range) }\end{array}$ & $\begin{array}{l}4.5 \mathrm{mmol} / \mathrm{L}[81 \mathrm{mg} / \mathrm{dL}],(0.3-17 \mathrm{mmol} / \mathrm{L} \\
[5.4-306 \mathrm{mg} / \mathrm{dL}])\end{array}$ \\
\hline Abnormal outcome, n (\%) & $\begin{array}{l}\text { 21/52 (40.4\%), of those } 2 \text { infants had mild, } \\
10 \text { had moderate and } 9 \text { had severe HIE }\end{array}$ \\
\hline Seizures & $12 / 52(23 \%)$ \\
\hline \multirow[t]{3}{*}{ Mortality } & Mild HIE: 0/25 \\
\hline & Moderate HIE: 2/18 (11\%) \\
\hline & Severe HIE: 2/9 (22\%) \\
\hline
\end{tabular}

Apgar scores were not available in 4 infants with planned home deliveries; $\mathrm{ETT}=$ Endotracheal tube; $\mathrm{CRP}=$ Cardiopulmonary resuscitation.

The mean (SD) number of blood glucose samples, taken in the first 72 hours, was 5.9 (2.9), 11.5 (5.7) and 13.1 (3.6) in infants with mild, moderate and severe HIE, respectively.

\section{Mean glucose levels and outcome}

Abnormal neuro-developmental outcome at 24 months of age was documented in $21(40.4 \%)$ infants. Mean (SD) blood glucose values did not differ between infants with normal or abnormal outcomes $[4.89(2.28) \mathrm{mmol} / \mathrm{L}$ and $5.02(2.35) \mathrm{mmol} / \mathrm{L}, \mathrm{p}$ value $=0.15]$ respectively. The distribution of blood glucose levels $(\mathrm{mmol} / \mathrm{L})$ in individual infants according to outcome is depicted in figure 2.

\section{HIE grade, glucose profile and outcome}

Mean (SD) of blood glucose level was 4.7 (1.8), 4.9 (2.4) and $5.3(2.5) \mathrm{mmol} / \mathrm{L}$ in infants with mild, moderate and severe HIE respectively, ( $\mathrm{p}$ value 0.10 ). The occurrence of early hypoglycaemia correlated significantly with severe HIE $(p=0.012)$. Twenty-five infants had mild HIE, of whom 23/25 (92\%) had a normal outcome. Moderate HIE occurred in 18 infants, of whom 10/18 (55.6\%) had abnormal outcome. The nine infants with severe HIE all had an abnormal outcome.

\section{Infants with normoglycaemia, hypoglycaemia and} hyperglycaemia and outcome (table 2 )

The relationship between early (0-6 hours of life) and late (6-72 hours of life) blood glucose levels and adverse outcome at 24 months of age in infants with HIE is presented in table 2. Early hypoglycaemia (0-6 hours of life) was associated with adverse outcome $(\mathrm{OR}=5.8,(\mathrm{CI}=$ 1.04-32). Late hypoglycaemia (between 6-72 hours of life) and early and late hyperglycaemia (0-6 and 6-72

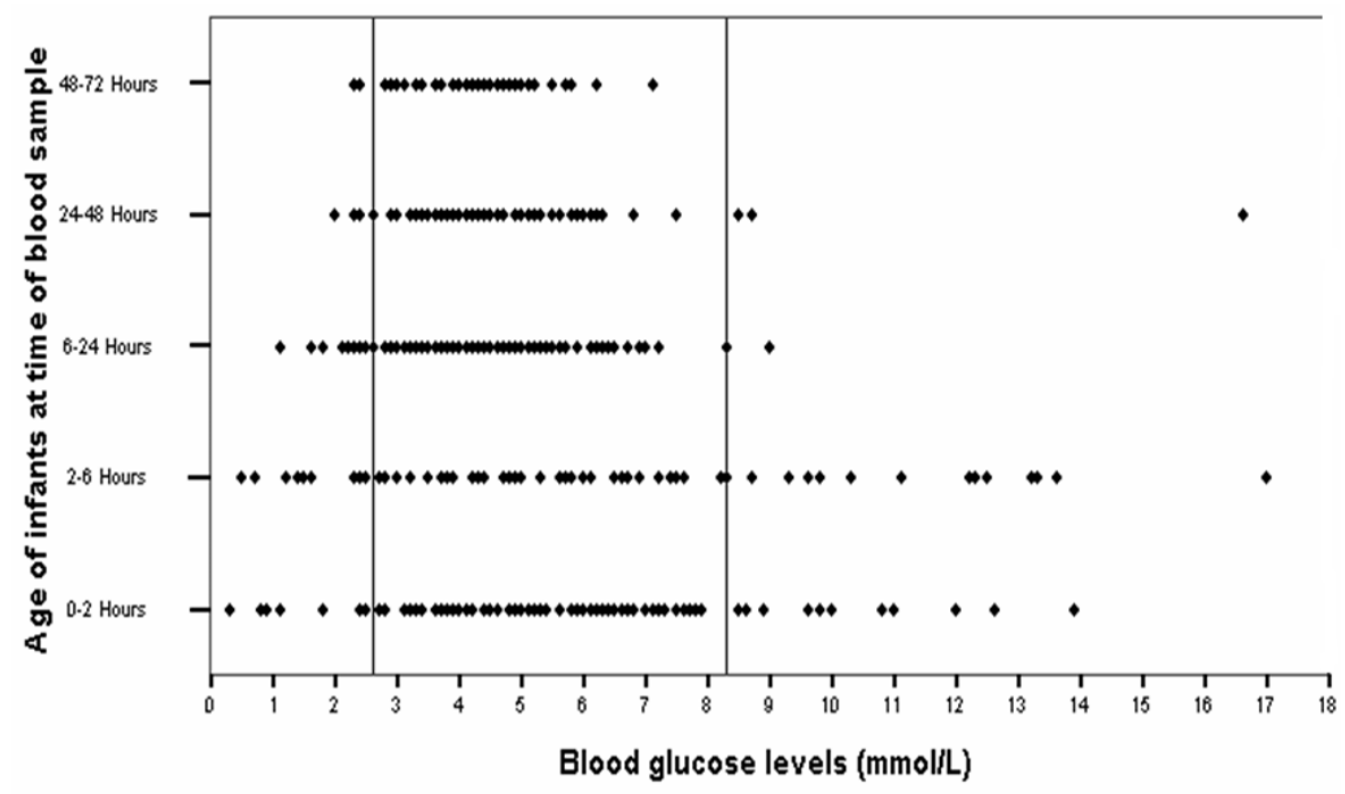

Figure 1 Distribution of blood glucose levels ( $\mathrm{mmol} / \mathrm{L}$ ) according to the timing of blood glucose sample after delivery. Horizontal lines represent normal range of blood glucose. 


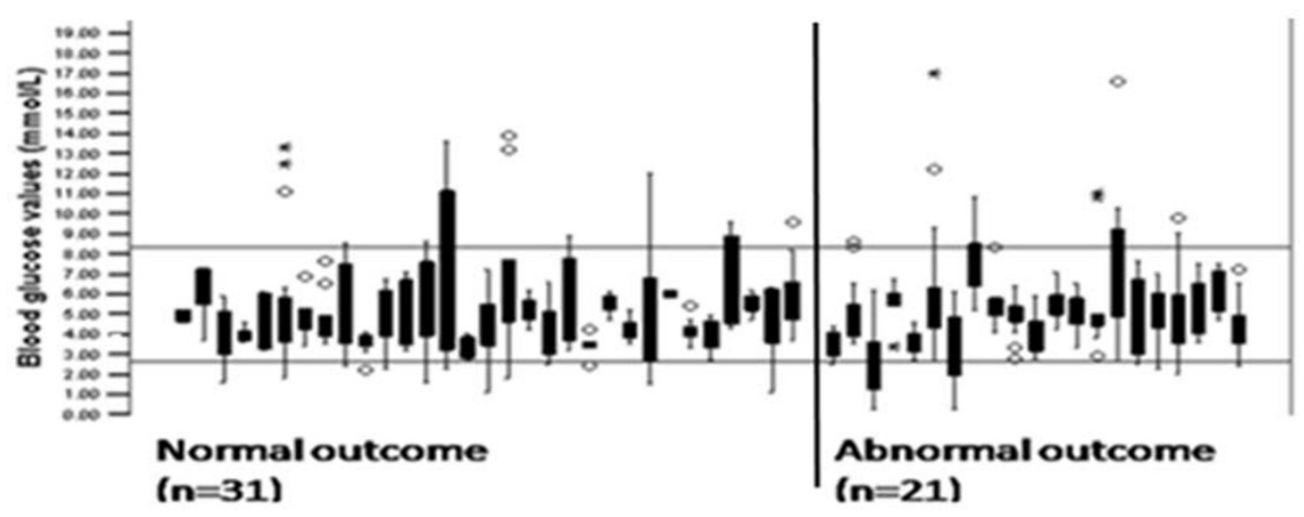

Figure 2 Distribution of blood glucose levels $(\mathrm{mmol} / \mathrm{L})$ in individual infants $(\mathrm{n}=52)$ by neurodevelopmental outcome at 24 months. Horizontal lines represent normal range of blood glucose. The boxes and whiskers represent the ranges between $25^{\text {th }}$ and $75^{\text {th }}$ percentiles and between $10^{\text {th }}$ and $90^{\text {th }}$ percentiles respectively. The circles (outliers) represent cases with values that are between 1.5 and 3 box lengths from either end of the box. Asterisks (extremes) represent cases with values more than 3 box lengths from rather end of the box.

hours of life, respectively) were not associated with adverse outcome (table 2). Univariate followed by multivariate analysis had been performed.

By univariate analysis, three variables were associated with adverse outcome: early hypoglycaemia, Apgar score $\leq 5$ at five minutes and severe HIE ( $\mathrm{p}$ value $0.025,0.035$ and $<0.001$ respectively). Moderate HIE, Apgar score at 1 minute, number of blood samples per subject and the requirement for intubation at birth were not significantly associated with adverse outcome. On multivariate analysis only moderate $(\mathrm{p}=0.024)$ and severe $(\mathrm{p}<$ 0.001 ) HIE grade remained significantly associated with adverse outcome.

\section{Discussion}

This study is the first to describe the blood glucose profile during the first 72 hours of life in infants with HIE. Despite a protocolised-driven approach to detecting and treating abnormal blood sugars following perinatal asphyxia in our unit, sustained normoglycaemia in the first 72 hours of birth was observed in only half of our infants with HIE.

What does the glucose profile in HIE tell us? Abnormal blood glucose values were observed in 1 out of 6 samples. Less than a third of hypoglycaemia and hyperglycaemia episodes were observed on the first blood sample taken within a half-hour of birth. However, half of hypoglycaemic samples and $90 \%$ of hyperglycaemic samples occurred within 6 hours of birth. These findings suggest that many asphyxiated babies, in addition to facing an hypoxic-ischaemic insult, are concurrently experiencing significant variations in blood sugars in the early newborn period. The hypoglycaemic episodes may be due to perinatal depletion of glycogen stores (many asphyxiated babies are post mature), whilst the hyperglycaemic episodes may reflect the release of stress-related hormones. In addition, since variations in blood glucose levels persist throughout the first 72 hours, this study indicates that regular measurements of the blood glucose should continue throughout this period.

In our study, early hypoglycaemia was associated with an increased risk of adverse outcome at 24 months of age in infants with HIE. However, when corrected for grade of HIE this was no longer significant. Our results are consistent with the findings of Salhab et al. In that study, hypoglycaemia on the initial blood sample after birth was associated with abnormal short-term outcomes (death as a consequence of severe encephalopathy and

Table 2 Relationship between blood glucose levels and adverse outcome in term infants with HIE ( $\mathbf{n}=\mathbf{5 2}$; however in 7 infants there were both hypoglycaemic and hyperglycaemic episodes documented, explaining the overlap)

\begin{tabular}{lccc}
\hline & No. of infants $(\mathbf{n}=\mathbf{5 2})$ & $\begin{array}{c}\text { No. of infants } \\
\text { With abnormal outcome }\end{array}$ & $\begin{array}{l}\text { Risk of adverse outcome } \\
\text { OR }(\mathbf{C l})\end{array}$ \\
\hline Normoglycaemia & $24 / 52$ & $9 / 24(37.5 \%)$ & $\mathrm{OR}=0.8,(\mathrm{Cl}=0.26-2.44)$ \\
\hline Early hypoglycaemia (0-6 hours of life) & $8 / 52$ & $6 / 8(75 \%)$ & $\mathrm{OR}=5.8,(\mathrm{Cl}=1.04-32)$ \\
\hline Late hypoglycaemia (6-72 hours of life) & $12 / 52$ & $2 / 12(8.3 \%)$ & $\mathrm{OR}=0.22,(\mathrm{Cl}=0.04-1.14)$ \\
\hline Early hyperglycaemia (0-6 hours of life) & $11 / 52$ & $4 / 11(36.4 \%)$ & $\mathrm{OR}=0.81,(\mathrm{Cl}=0.2-3.2)$ \\
\hline Late hyperglycaemia (6-72 hours of life) & $4 / 52$ & $2 / 4(50 \%)$ & $\mathrm{OR}=1.53,(\mathrm{Cl}=0.2-11.8)$ \\
\hline
\end{tabular}


evidence of moderate to severe encephalopathy with or without seizures) in term infants with severe fetal acidaemia [9]. However no long term outcome has been reported from that group. In preterm infants, it has been shown that hypoglycaemia was associated with mental and motor development scores at age of 18 months corrected. However at age of 8 years, only arithmetic and motor scores were affected [5,25]. It has been shown that intracranial MRI abnormalities in full term infants with neonatal hypoglycaemia are resolved two months later [26]. Hypoglycaemia has been associated with abnormal neurological outcomes but not with abnormal psychomotor development $[3,27,28]$.

Available data on the relationship between hyperglycaemia and adverse outcome is inconclusive [13,15]. In infant rats, it has been shown that hyperglycaemia during an hypoxic-ischaemic insult can have a beneficial effect against brain injury [29]. LeBlanc et al showed that, in newborn piglets, hyperglycaemia after hypoxicischaemic injury does not worsen the brain injury [30]. In newborn piglets, Park et al showed that brain energy metabolism was affected by hyperglycaemia during the immediate reperfusion period after hypoxic-ischaemic brain insult [21]. In fetal sheep, Blomstrand $S$ et al showed that hyperglycemia during asphyxia reduces cerebral oxygen consumption and increases acidosis [22]. Hyperglycaemia following hypoxia-ischaemia insult was shown to be harmful, in adult rats [23].

However the glucose values studied were beyond those we see in clinical situation in humans. Despite the data on ELBW infants [13-15] and experience with older children $[16,17]$, the ideal management of hyperglycaemia in neonatal encephalopathy remains unclear $[19,20]$.

There are some limitations to the current study. Data was available in only 52 patients who are part of an ongoing study of continuous early EEG in HIE. The association between blood glucose and neuro-developmental outcome was not an a priori outcome in this study. Standard blood sampling was not possible, since in emergency situations, blood glucose samples were collected from arterial, capillary or venous blood which may independently affect glucose levels. Initial blood glucose samples were collected within 30 and 100 minutes after delivery in inborn and outborn infants respectively. These were repeated between 30 minutes and 4 hours, as clinically indicated. It is, therefore, possible that there were variations in blood glucose values that were missed in between measurements. Finally this cohort of neonates with HIE was recruited prior to introduction of therapeutic hypothermia as a standard of care. Whether variations in blood glucose will affect neuro-developmental outcome in infants treated with therapeutic hypothermia remains to be seen.

\section{Conclusion}

We conclude that it is difficult to avoid hypoglycaemia and/or hyperglycaemia in infants with HIE, since such variations in blood glucose levels often occur soon after birth, and may be related to the asphyxial process. In term infants with HIE, glucose profiles vary widely during the first 72 hours of life. Early hypoglycaemia occurs more frequently in infants with severe HIE, and is therefore associated with abnormal outcome. The further exploration of the relationship between glycaemic control and neurological outcome will require larger numbers of patients and continuous blood glucose monitoring.

\section{Acknowledgements}

GB was supported by a Principal Investigator Career Advancement Award [PICA/1836/06] from Science Foundation Ireland. DM was supported by the Denis O'Sullivan, Clinical Investigator Fellowship (UCC).

\section{Author details}

${ }^{1}$ Neonatal Intensive Care Unit, Cork University Maternity Hospital, Cork, Ireland. ${ }^{2}$ Department of Paediatrics \& Child Health, University College Cork, Cork, Ireland.

\section{Authors' contributions}

MN has made contributions to collect the data from the charts and to analysis and interpretation of the data. He is the main author of the manuscript. DM participated in the design of the study, recruitment, and neurodevelopmental follow up. DM has made contributions to analysis and interpretation of the data and participated in drafted the manuscript. GB in the design of the study, infant recruitment, study and follow up. GB has participated in drafted the manuscript. ED has made contributions to analysis and interpretation of the data, manuscript draft and critical appraisal. CAR participated in the design of the study, infant recruitment and follow up. He has participated in drafting the manuscript and revising it critically for important intellectual content and has given final approval of the version to be published. All authors read and approved the final manuscript.

\section{Competing interests}

The authors declare that they have no competing interests.

Received: 4 October 2010 Accepted: 4 February 2011

Published: 4 February 2011

\section{References}

1. Vannucci RC: Hypoxic-ischemic encephalopathy. Am J Perinato/ 2000, 17:113-20.

2. Glass HC, Ferriero DM: Treatment of hypoxic-ischemic encephalopathy in newborns. Curr Treat Options Neurol 2007, 6:414-23.

3. Caraballo RH, Sakr D, Mozzi M, et al: Symptomatic occipital lobe epilepsy following neonatal hypoglycemia. Pediatr Neurol 2004, 31:24-9.

4. Burns CM, Rutherford MA, Boardman JP, et al: Patterns of cerebral injury and neurodevelopmental outcomes after symptomatic neonatal hypoglycemia. Pediatrics 2008, 122:65-74.

5. Lucas A, Morley R, Cole TJ: Adverse neurodevelopmental outcome of moderate neonatal hypoglycaemia. BMJ 1988, 297:1304-8.

6. Hawdon JM: Hypoglycaemia and the neonatal brain. Eur J Pediatr 1999, 158(Suppl 1):S9-S12.

7. Rozance PJ, Hay WW: Hypoglycemia in newborn infants: Features associated with adverse outcomes. Biol Neonate 2006, 90(2):74-86.

8. Basu P, Som S, Choudhuri N, et al: Contribution of the blood glucose level in perinatal asphyxia. Eur J Pediatr 2009, 168(7):833-8.

9. Salhab WA, Wyckoff MH, Laptook AR, et al: Initial hypoglycemia and neonatal brain injury in term infants with severe fetal acidemia. Pediatrics 2004, 114:361-6. 
10. Park TS, Gonzales ER, Shah AR, et al: Hypoglycemia selectively abolishes hypoxic reactivity of pial arterioles in piglets: role of adenosine. Am J Physiol 1995, 268:H871-8.

11. McGowan JE, Chen L, Gao D, et al: Increased mitochondrial reactive oxygen species production in newborn brain during hypoglycemia. Neurosci Lett 2006, 399(1-2):111-4.

12. Auer RN: Hypoglycemic brain damage. Metab Brain Dis 2004, 19(34):169-75.

13. Blanco CL, Baillargeon JG, Morrison RL, et al: Hyperglycemia in extremely low birth weight infants in a predominantly Hispanic population and related morbidities. J Perinatol 2006, 26:737-41.

14. Kao $L S$, Morris $B H$, Lally KP, et al: Hyperglycemia and morbidity and mortality in extremely low birth weight infants. J Perinatol 2006, 26:730-6.

15. Hays SP, Smith EO, Sunehag AL: Hyperglycemia is a risk factor for early death and morbidity in extremely low birth-weight infants. Pediatrics 2006, 118:1811-8.

16. Klein GW, Hojsak JM, Schmeidler J, et al: Hyperglycemia and outcome in the pediatric intensive care unit. J Pediatr 2008, 153:379-84.

17. Lodha R, Bhutia TD, Kabra SK, et al: Day 1 blood glucose and outcome in critically ill children. Indian Pediatr 2009, 46:809-10.

18. Alvarez-Sabín J, Molina CA, Ribó M, et al: Impact of admission hyperglycemia on stroke outcome after thrombolysis: risk stratification in relation to time to reperfusion. Stroke 2004, 35:2493-8.

19. Collins JW, Hoppe M, Brown K, et al: A controlled trial of insulin infusion and parenteral nutrition in extremely low birth weight infants with glucose intolerance. J Pediatr 1991, 118(6):921-7.

20. Vlasselaers D, Milants I, Desmet $L$, et al: Intensive insulin therapy for patients in paediatric intensive care: a prospective, randomised controlled study. Lancet 2009, 373(9663):547-56.

21. Park WS, Chang YS, Lee M: Effects of hyperglycemia or hypoglycemia on brain cell membrane function and energy metabolism during the immediate reoxygenation-reperfusion period after acute transient global hypoxia-ischemia in the newborn piglet. Brain Res 2001, 901:102-8.

22. Blomstrand $\mathrm{S}$, Hrbek $\mathrm{A}$, Karlsson $\mathrm{K}$, et al: Does glucose administration affect the cerebral response to fetal asphyxia? Acta Obstet Gynecol Scand 1984, 63(4):345-53

23. Lin B, Ginsberg MD, Busto R: Hyperglycemic exacerbation of neuronal damage following forebrain ischemia: microglial, astrocytic and endothelial alterations. Acta Neuropathol 1998, 96(6):610-20.

24. Barnett AL, Guzzetta A, Mercuri E, et al: Can the Griffiths scales predict neuromotor and perceptualmotor impairment in term infants with neonatal encephalopathy? Arch Dis Child 2004, 89:637-643.

25. Cornblath M, Schwartz R: Outcome of neonatal hypoglycaemia. Complete data are needed. BMJ 1999, 318:194-5, Reply by Lucas A, Morley R. BMJ 1999; 318:195.

26. Kinnala A, Rikalainen $\mathrm{H}$, Lapinleimu $\mathrm{H}$, et al: Cerebral magnetic resonance imaging and ultrasonography findings after neonatal hypoglycemia. Pediatrics 1999, 103:724-9.

27. Koh TH, Aynsley-Green A, Tarbit M, et al: Neural dysfunction during hypoglycaemia. Arch Dis Child 1988, 63:1353-8.

28. Brand PL, Molenaar NL, Kaaijk C, et al: Neurodevelopmental outcome of hypoglycaemia in healthy, large for gestational age, term newborns. Arch Dis Child 2005, 90:78-81.

29. Simpson IA, Carruthers A, Vannucci SJ: Supply and demand in cerebral energy metabolism: the role of nutrient transporters. I Cereb Blood Flow Metab 2007, 27(11):1766-91.

30. LeBlanc MH, Huang M, Patel D, Smith EE, Devidas M: Glucose given after hypoxic ischemia does not affect brain injury in piglets. Stroke 1994, 25(7):1443-7.

\section{Pre-publication history}

The pre-publication history for this paper can be accessed here: http://www.biomedcentral.com/1471-2431/11/10/prepub

doi:10.1186/1471-2431-11-10

Cite this article as: Nadeem et al.: Early blood glucose profile and neurodevelopmental outcome at two years in neonatal hypoxicischaemic encephalopathy. BMC Pediatrics 2011 11:10.

\section{Submit your next manuscript to BioMed Central and take full advantage of:}

- Convenient online submission

- Thorough peer review

- No space constraints or color figure charges

- Immediate publication on acceptance

- Inclusion in PubMed, CAS, Scopus and Google Scholar

- Research which is freely available for redistribution

Submit your manuscript at www.biomedcentral.com/submit 